\title{
The impact of exposure to pesticides on the risk of gastrointestinal cancer among pistachio farmers; a case- control study
}

\author{
Vazirinejad $\mathrm{R}, \mathrm{PhD}^{1}$, Khalili P, $\mathrm{MSc}^{2 *}$, Rezaeian $\mathrm{M}, \mathrm{PhD}^{3}$, Jamalizadeh A, $\mathrm{MD}^{4}$, Puorkarami \\ $\mathrm{AH}, \mathrm{BSc}^{5}$, \\ 1- Professor, PhD of Epidemiology, Social Social Determinants Of Health Research Centre, Medical School, Rafsanjan \\ University of Medical Science, Rafsanjan, Iran. 2- MSc in Epidemiology, Rafsanjan University Of Medical Sciences, \\ Rafsanjan, Iran. 3- Professor, Dept. of Epidemiology and Biostatistics, Occupational Environmental Research Center, \\ Medical School, Rafsanjan University of Medical Sciences, Rafsanjan, Iran. 4- General Physician, Rafsanjan University of \\ Medical Sciences, Iran. 5- Export, Rafsanjan University of Medical Sciences, Rafsanjan, Iran.
}

Received: February 2016, Accepted: February 2016

Background: Gastrointestinal cancers are among the most common cancers in different communities. Gastrointestinal tract cancer is the most common cancer among Iranian men and the second common cancer among Iranian women. Due to the impact of environmental factors on the risk of gastrointestinal cancer and the increasing use of agricultural pesticides, this study aimed to investigate the effects of exposure to pesticides on gastrointestinal cancer among pistachio farmers, Rafsanjan, Iran

Materials and Methods: In this case-control study, 79 patients with gastrointestinal cancer (cases) and 143 healthy people (controls) were studied. For each case, two people were selected as controls for each case from their neighbors and relatives. Data were collected using the study checklist which included demographic information and specific items related to their exposure. Data were analyzed using independent t-test, chi-square test, Fisher's exact test, and logistic regression.

Results: The risk of gastrointestinal cancer after controlling some confounding factors among individuals who were exposed to spraying pesticides for less than 10 days per year was 1.38 (CI: 0.70-2.71), and in individuals who were exposed to it for between 10 to 20 days per year was 1.71 (CI: 0.79-3.7). The difference was not statistically significant . However, for individuals who had this exposure for more than 20 days per year, the risk was increased to 8.53 (CI: 2.1-34.7) which was statistically significant $(\mathrm{P}=0.004)$. Unexpected exposure to agricultural pesticides and living close to pistachio gardens, both significantly $(\mathrm{P}<0.05)$ increased the risk of gastrointestinal cancers by 8.67 (CI: 1-75.71) and 2.7 (CI: 1.43-5.1), respectively. Among subjects who used protective equipment, the risk of gastrointestinal cancer was statistically lower $(\mathrm{OR}=0.18,95 \% \mathrm{CI}$ : $0.042-0.85)$ than this risk among people who did not use this equipment $(\mathrm{P}=0.03)$.

Conclusions: Our findings showed that exposure to pesticides, in particular for long time, increased the risk of gastrointestinal cancer among pistachio farmers. Further studies in this area are recommended.

Keywords: Gastrointestinal Tract Cancer, Toxins, Pistachios, Iran.

\section{Introduction}

Despite some success in preventing infectious diseases in recent decades, there has been an increasing incidence of chronic diseases. In some countries after cardiovascular disease, cancer is the second leading cause of death (1). Gastrointestinal cancer is among the most common types of cancer in different communities. In the United States of America, after prostate cancer, gastrointestinal tract cancer is the second most common noncutaneous cancer (2). In Iran, cancer is the third most common cause of death, and 30000

\footnotetext{
Corresponding author: Parvin Khalili, Rafsanjan University of Medical Sciences, Rafsanjan, Iran. Email: parvinkhalili61@yahoo.com
} 
people die from cancer each year (3). Gastrointestinal tract cancer is the most common cancer among Iranian men and it is the second most common cancer among Iranian women $(4,5)$.

Every year, 50000 people are diagnosed with cancer in Iran and the organ most involved is the gastrointestinal tract (by more than $38 \%$ of all cancers). Cancers of the stomach, esophagus, and colon are the three most common cancers in men and women, after breast cancer, these three types of cancer are among the most commonly reported cancers (6). In Iran, nearly half of all deaths due to cancers are related to gastrointestinal cancers (3).

The two main causes of cancer are genetic and environmental factors, and the environmental factors are controllable and preventable (7). Environmental and climatic conditions in different regions provide the underlying factors for some diseases including cancer (8). One of the risk factors associated with gastrointestinal cancer that has been investigated in various studies is exposure to agricultural pesticides (9). Pesticides are chemicals that are used to minimize the effects of harmful organisms such as insects, rodents, weeds, and fungi that live around humans. Rafsanjan is an area with abundant agricultural lands and about 88 thousand hectares of pistachio gardens. Therefore, about 700 tons of pesticides for pistachios are used in this city every year (10). In a study conducted by Vazirinezhad et al. on the geographical distribution of death due to cancer in the city of Rafsanjan and Anar (Iran), a clear difference was observed in mortality due to cancer between parts of Rafsanjan which had greater accumulation of pistachio gardens compared to other parts of the city. This study strengthens the hypothesis of the relationship between exposure to pesticides of pistachios and cancer (the article is being published). Thus, the present study aimed to investigate the effects of exposure to pesticides of pistachios on gastrointestinal cancer in the city of Rafsanjan and Anar.

\section{Material and Methods}

This was a case-control study conducted on 222 individuals aged between 20-29 years who lived in four districts of the city of Rafsanjan. In this study, the sample size was calculated using the formula of the minimum sample size for comparison of the two communities, with the power of $90 \%$ and error of 0.05 , and the number 79 was calculated for each group.

$n=\frac{\left(Z_{1-\alpha / 2}+Z_{1-\beta}\right)^{2}\left[P_{1}\left(1-P_{1}\right)+P_{2}\left(1-P_{2}\right)\right]}{\left(P_{1}-P_{2}\right)^{2}}$

In this formula, the approximate ratio of patients with gastrointestinal cancer (case group) who had been exposed to pistachio pesticides and the approximate ratio of healthy individuals (control group) who were exposed to pistachio pesticides, according to a pilot study on two groups of 10 individuals from the case and control groups, were calculated as 0.7 and 0.44 , respectively. In this study, the number of individuals invited for the control group was twice that for the case group and a total of 222 patients were enrolled in the study. Individuals who had been diagnosed with gastrointestinal cancer between the years 2009 and 2014 by pathology centers and their names were recorded in the health department of the university were selected as the case group. Moreover, for each individual in the case group, two witnesses (control), including neighbors and relatives, were selected.

The inclusion criteria included being Iranian and aged 20-90 years. The two groups were matched in terms of confounding variables such as age, gender, socioeconomic status, and place of residence. Data was collected by trained health care providers during 2 months through interviews with the participants. The checklist used in this study included demographic and general information, information on agricultural activities, exposure to pesticides, and occupational information. The information of the checklist, after collection and coding, was entered into SPSS 
software (version 21, SPSS Inc., Chicago, IL, USA). To compare the mean quantitative factors in the two groups, independent twosample t-test was used. To compare the frequency distribution of qualitative variables in the two groups, chi-square or Fisher's exact test was used. Then, using the logistic regression and logistic regression multivariate model, the relationship between exposure to pesticides of pistachios and gastrointestinal tract cancer were evaluated after excluding confounding factors such as smoking. In the final logistic regression model, the relationship between exposure to pesticides of pistachios and cancer of the gastrointestinal tract was reported as OR (Odds Ratio) and 95\% confidence interval for $\mathrm{OR}$ and $\mathrm{P}$-value to evaluate the significance of the relationship. In this study, the significance level was 0.05 .

\section{Results}

No significant differences were observed between the variables of age (mean age of the subjects in the case group was $61.18 \pm 15.91$ years and in the control group was $60.92 \pm$ 15.02 years), gender, and place of residency. However, in terms of tobacco consumption, there was a statistically significant difference between the two groups (Table 1). Since smoking was a confounding factor in this study, this factor was controlled in the analysis phase. The findings of this study showed that $69.6 \%$ and $58 \%$ of the case and control group participants had performed agricultural activities and this difference was not statistically significant based on the chi-square test $(\mathrm{P}=0.089)$. Independent t-test results showed that the mean duration of agricultural activity in the case group was $28 \pm 23$ years and in the control group was $23 \pm 23$ years and this difference was not statistically significant $(\mathrm{P}=0.150)$. The mean number of days/years of pesticide spraying in the case group was $13.21 \pm 20.91$ and in the control group was $5.38 \pm 9.51$ and this difference was statistically significant $(\mathrm{P}=0.003)$.

Table 1: Distribution of subjects in the two groups in terms of demographic variables

\begin{tabular}{|c|c|c|c|c|c|c|}
\hline \multirow{2}{*}{\multicolumn{2}{|c|}{ Variables }} & \multicolumn{2}{|c|}{ Case group } & \multicolumn{2}{|c|}{ Control group } & \multirow{2}{*}{ P-Value } \\
\hline & & $\mathbf{N}$ & $\%$ & $\mathbf{N}$ & $\%$ & \\
\hline \multirow{5}{*}{ Age } & $<40$ & 8 & 10.1 & 13 & $9 / 00$ & \multirow{5}{*}{0.9} \\
\hline & $40-49$ & 9 & 11.4 & 17 & 11.9 & \\
\hline & $50-59$ & 16 & 20.3 & 27 & 18.9 & \\
\hline & 60-69 & 21 & 26.6 & 44 & 30.8 & \\
\hline & $70<$ & 25 & 31.6 & 42 & 29.4 & \\
\hline \multirow{2}{*}{ Gender } & Female & 19 & 24.1 & 36 & 25.2 & \multirow{2}{*}{0.75} \\
\hline & Male & 60 & 75.9 & 107 & 74.8 & \\
\hline \multirow{2}{*}{ Place of residency } & City & 13 & 16.5 & 38 & 26.8 & \multirow{2}{*}{0.081} \\
\hline & Village & 66 & 83.5 & 105 & 73.2 & \\
\hline \multirow{2}{*}{ Smoking } & Yes & 34 & 43 & 32 & 22.4 & \multirow{2}{*}{0.001} \\
\hline & No & 45 & 57 & 111 & 77.6 & \\
\hline
\end{tabular}

Based on the logistic regression model, the risk of gastrointestinal tract cancer in people who were involved in pesticide spraying programs, after controlling the confounding factor of smoking, was 1.64 (CI: 0.9-2.99) and was not statistically significant $(\mathrm{P}=0.100)$ (Table 2). In table 2 , the relationship between the variables of exposure to pesticides and gastrointestinal tract cancer, in raw and adjusted mode, has been shown for the confounding variable of smoking. Based on the number of days/years of pesticide spraying, the risk of the gastrointestinal tract cancers was 1.38 (CI: 0.70-2.71) in people who had worked less than 10 days in that environment and 1.71 (CI: 0.79-3.7) in people 
who had worked between 10 to 20 days. This difference was not statistically significant. Nevertheless, for the participants who had worked for more than 20 days, the risk was 8.53 (CI: 2.1-34.7), which was statistically significant $(\mathrm{P}=0.004)$. These findings showed that with the increase in the number of days that a person participates in the pesticide program, the risk of gastrointestinal cancer also increased. This showed the impact of the severity and duration of exposure to pesticides on gastrointestinal tract cancer.

Table 2: The relationship between the variables of exposure to pesticides and cancer of the gastrointestinal tract in raw and adjusted mode for the confounding variable of smoking

\begin{tabular}{|c|c|c|c|c|c|c|}
\hline \multirow[b]{2}{*}{ Variables } & & \multicolumn{2}{|c|}{ Univariable } & \multicolumn{2}{|c|}{ Multivariable } & \multirow{2}{*}{$\begin{array}{c}\text { Hosmer-Lemeshow } \\
\text { goodness- of- fit } \\
\text { test }\end{array}$} \\
\hline & & $\begin{array}{l}\text { OR(95\% CI for } \\
\text { OR })\end{array}$ & P-Value & $\begin{array}{l}\text { OR(95\% CI for } \\
\text { OR })\end{array}$ & P-Value & \\
\hline \multirow{2}{*}{$\begin{array}{l}\text { Presence in pesticide } \\
\text { spraying programs }\end{array}$} & NO & 1 & - & 1 & - & \multirow{2}{*}{0.89} \\
\hline & Yes & $1.71(0.95-3.081)$ & 0.074 & $1.64(0.9-2.99)$ & 0.1 & \\
\hline \multirow{4}{*}{$\begin{array}{c}\text { Number of days/years } \\
\text { of pesticide spraying } \\
\text { program }\end{array}$} & $\mathbf{0}$ & 1 & - & 1 & - & \multirow{4}{*}{0.94} \\
\hline & $1-9$ & $1.44(0.74-2.8)$ & 0.28 & $1.38(0.7-2.71)$ & 0.28 & \\
\hline & $10-20$ & $1.88(0.88-3.96)$ & 0.1 & $1.77(0.79-3.7)$ & 0.1 & \\
\hline & $20<$ & $7.79(1.96-30.92)$ & 0.004 & $8.53(2.1-34.7)$ & 0.004 & \\
\hline \multirow{2}{*}{$\begin{array}{l}\text { Unexpected exposure to } \\
\text { agricultural pesticides }\end{array}$} & NO & 1 & - & 1 & - & \multirow{2}{*}{0.99} \\
\hline & Yes & $11.67(1.38-98.77)$ & 0.024 & $8.67(1-75.71)$ & 0.05 & \\
\hline \multirow{2}{*}{$\begin{array}{c}\text { The use of personal } \\
\text { protective equipment }\end{array}$} & NO & 1 & - & 1 & - & \multirow{2}{*}{0.73} \\
\hline & Yes & $0.19(0.043-0.86)$ & 0.03 & $0.18(0.042-0.85)$ & 0.03 & \\
\hline \multirow{2}{*}{ Distance of the location } & $100<$ & 1 & - & 1 & - & \multirow{2}{*}{0.94} \\
\hline & $100>$ & $2.56(1.46-4.69)$ & 0.002 & $2.59(1.43-4.8)$ & 0.002 & \\
\hline \multirow{2}{*}{ Permethrin } & NO & 1 & - & 1 & - & \multirow{2}{*}{0.9} \\
\hline & Yes & $4.5(1.64-12.36)$ & 0.002 & $5.37(1.9-15.17)$ & 0.001 & \\
\hline \multirow{2}{*}{ Amitraz } & NO & 1 & - & 1 & - & \multirow{2}{*}{0.95} \\
\hline & Yes & $1.95(1.11-3.45)$ & 0.02 & $1.86(1.04-3.32)$ & 0.037 & \\
\hline \multirow{2}{*}{ Endosulfan } & NO & 1 & - & 1 & - & \multirow{2}{*}{0.89} \\
\hline & Yes & $1.79(1-3.087)$ & 0.042 & $1.73(1.73-3.087)$ & 0.05 & \\
\hline
\end{tabular}

Regarding unexpected exposure to agricultural pesticides, the chances of developing gastrointestinal tract cancer was 8.67 (CI: 175.71) and was statistically significant ( $P$ $=0.050$ ). Furthermore, for individuals who used personal protective equipment, the risk of gastrointestinal tract cancer was 0.18 (CI: $0.042-0.85)$ and this variable was statistically significant $(\mathrm{P}=0.030)$ and showed the role of protection in digestive tract cancer. Regarding the place of residency, people who lived less than 100 meters from the pistachio gardens had 2.59 chance of developing gastrointestinal tract cancer (CI: 1.43-4.8) and this was statistically significant $(P=0.002)$. Another important variable in this study was the type of pesticide, and the results indicated that the risk of gastrointestinal tract cancer in individuals who were exposed to amitraz, endosulfan, and permethrin (ambush) was 95\% (OR 1.86, 95\% CI: $1.04-3.32$ ), $80 \%$ (OR 1.73 , 95\% CI: $1.73-$ 3.087), and 350\% (OR 5.37, 95\% CI: 1.915.17), respectively, in comparison to individuals who were not exposed to these pesticides. There were no significant differences among the two groups regarding exposure to other pesticides $(\mathrm{P}>0.050)$ (Table $3)$. 
Table 3: Frequency distribution of the subjects in the two groups in terms of exposure to different pesticides

\begin{tabular}{|c|c|c|c|c|c|c|c|}
\hline \multirow{2}{*}{ Variables } & & \multicolumn{2}{|c|}{ Case group } & \multicolumn{2}{|c|}{ Control group } & \multirow{2}{*}{$\begin{array}{c}\text { OR } \\
(95 \% \text { CI for OR) }\end{array}$} & \multirow{2}{*}{ P-Value } \\
\hline & & $\mathbf{N}$ & $\%$ & $\mathbf{N}$ & $\%$ & & \\
\hline \multirow{2}{*}{ Endosulfan } & Yes & 51 & 64.6 & 72 & 50.3 & \multirow{2}{*}{$1.79(1.020-3.162)$} & \multirow{2}{*}{0.04} \\
\hline & No & 28 & 35.4 & 71 & 49.7 & & \\
\hline \multirow[t]{2}{*}{ Amitraz } & Yes & 52 & 65.8 & 71 & 49.7 & \multirow{2}{*}{$1.95(1.106-3.45)$} & \multirow{2}{*}{0.02} \\
\hline & No & 27 & 34.2 & 72 & 50.3 & & \\
\hline \multirow{2}{*}{ Dursban } & Yes & 12 & 15.2 & 21 & 14.7 & \multirow{2}{*}{$1.041(0.48-2.25)$} & \multirow{2}{*}{0.92} \\
\hline & No & 67 & 84.8 & 122 & 85.3 & & \\
\hline \multirow{2}{*}{ Zolone } & Yes & 41 & 51.9 & 64 & 44.8 & \multirow{2}{*}{$1.33(0.77-2.31)$} & \multirow{2}{*}{0.31} \\
\hline & No & 38 & 48.1 & 79 & 55.2 & & \\
\hline \multirow{2}{*}{ Sumithion } & Yes & 4 & 5.1 & 7 & 4.9 & \multirow{2}{*}{$1.036(0.29-3.65)$} & \multirow{2}{*}{1} \\
\hline & No & 75 & 94.9 & 136 & 95.1 & & \\
\hline \multirow{2}{*}{ Diazinon } & Yes & 20 & 25.3 & 41 & 28.7 & \multirow{2}{*}{$0.84(0.45-1.57)$} & \multirow{2}{*}{0.59} \\
\hline & No & 59 & 74.7 & 102 & 71.3 & & \\
\hline \multirow[t]{2}{*}{ Mospilan } & Yes & 10 & 12.7 & 20 & 14 & \multirow{2}{*}{$0.89(0.395-2.012)$} & \multirow{2}{*}{0.78} \\
\hline & No & 41 & 51.9 & 85 & 59.4 & & \\
\hline \multirow{2}{*}{ Ethion } & Yes & 38 & 48.1 & 58 & 40.6 & \multirow{2}{*}{$1.36(0.78-2.36)$} & \multirow{2}{*}{0.28} \\
\hline & No & 41 & 51.9 & 85 & 59.4 & & \\
\hline \multirow{2}{*}{ Permethrin } & Yes & 13 & 16.5 & 6 & 4.2 & \multirow{2}{*}{$4.5(1.64-12.4)$} & \multirow{2}{*}{0.002} \\
\hline & No & 66 & 83.5 & 137 & 95.8 & & \\
\hline
\end{tabular}

\section{Discussion}

The results of the present study showed that to two groups were matched regarding the confounding variables. There were no significant differences between the two groups in terms of agricultural activity, duration of agricultural activity in years, and history of attendance in pesticide spraying programs. However, increase in days/years of exposure to pesticides, unexpected exposure to pesticides, and lack of use of personal protective equipment when working with pesticides increased the risk of digestive tract cancers. The risk of gastrointestinal cancer in people who lived near the agricultural gardens had significantly increased.

In the study by Salerno on the relationship between agricultural pesticides and risk of cancer in one of the cities of Italy, there was a possible link between exposure to pesticides and cancer and the results were inconsistent with the present study (11). Alexander, in a case study with the aim of identifying the effect of pesticides on the risk of colorectal cancer, showed that there were no significant relationships between exposure to agricultural pesticides and colon and rectal cancer (12).
However, relationships were observed in the separate analysis of different pesticides, but there were limitations in determining this relationship. Based on the results no causal link was observed between exposure to agricultural pesticides and colon and rectum cancer, which was consistent with the findings of this study (12).

A study was conducted to assess the impact of pesticides on gastric and esophageal cancers in southwest Turkey by Yildirim et al. (13). Their results showed no statistically significant relationship between exposure to pesticides and esophagus and stomach cancer and this finding was consistent with the findings of the present study (13). It should be noted that perhaps the lack of a significant relationship between gastrointestinal tract cancers and the history of and mean duration of working in agriculture in terms of years in the present study, and its inconsistency with other studies, might be due to the fact that most people in this region identify themselves as farmers, but may not perform any agricultural activities. Regarding the variable of experience in the pesticide spraying program, it should be noted that the number of days/years of spraying differed between individuals. In other words, 
individuals differed in terms of duration and intensity of exposure to pesticides. This could be one of the reasons of the insignificancy of the relationships; this is why the mean of the days/years of spraying was compared in both groups. This difference was statistically significant and this relationship showed the impact of the duration and intensity of exposure to pesticide of pistachio. In this study, the number of days/years of pesticide spraying in people was divided into four subgroups. The findings showed that with increase in the number of days that people participate in the pesticide spraying program, the risk of gastrointestinal tract cancer also increases. In addition, the risk of gastrointestinal tract cancer in individuals who were unexpectedly exposed to high doses of pesticides was 12 times higher than others. Andreotti investigated the effect of exposure to pesticides on pancreatic cancer, and showed that with increase in the number of days of exposure to pesticides per year, the risk of this cancer increased even after controlling confounding variables such as smoking, diabetes, and age (14). These results were consistent with the present study (14).

Rusiecki showed that with increase in the amount of exposure to pesticides, the risk of non-Hodgkin lymphoma also increased (15). The results of the present study showed increased risk of gastrointestinal cancers in people who were at the highest level of exposure to pesticides. These findings were consistent with the results of some studies on the effects of different levels of exposure to pesticides on gastrointestinal cancers (16-21). The results of this study showed that the risk of gastrointestinal cancer in individuals who had been exposed to amitraz, endosulfan, and ambush was 95\%, 80\%, and $350 \%$ in comparison to those who were not exposed to these toxins. No significant differences were observed between the two groups regarding exposure to other pesticides.

The results of the case study by Weichenthal on the relationship between exposure to pesticides and kidney cancer through reviewing 28 studies was consistent with the present study. No statistically significant relationships were observed between use of pesticides and the risk of cancer. However, in some of these studies, a significant association was observed in higher levels of exposure to 12 types of pesticides, including permethrin (22).

Endosulfan is a chlorinated organic insecticide and it is used in numerous agricultural products in many areas of the world to control a wide variety of pests and arthropod. Endosulfan is easily absorbed by humans through the stomach, lungs, and skin. This pesticide can cause acute and chronic toxicity in humans. Laboratory studies have shown that endosulfan has potential carcinogenic effects (23). This pesticide is responsible for a large number of deaths due to pesticide poisoning throughout the world. Whether endosulfan can cause cancer in humans is a controversial issue (24).

There are evidences of carcinogenic toxins in amitraz. The Environmental Protection Agency issued a list of toxins in September 2015 that can cause cancer in humans and amitraz was also included in this list (25). Although amitraz and endosulfan are no longer used international community, according to the statistics obtained from the Agricultural Jihad in the area under review, they are currently the most frequently used pesticides in this city. Due to the high toxicity and deleterious effects of these toxins on human health and the environment, endosulfan since the end of the year 2011 and amitraz since September 2012 have been excluded from the list of permitted pesticides of the country, but unfortunately they are still used in this city and are available in their warehouses (10).

Thus, according to the results of this study and other studies, attempting to set a schedule to reduce the sale and use of pesticides, the use of other methods to control agricultural pests, providing cheap and affordable protection equipment, preparation of appropriate educational materials through mass media, training health staff and education department 
personnel on the effects of pesticides, especially in rural areas, and encouraging and teaching farmers to use low-risk pesticides appear necessary (26). There is also a critical need for studies and research on exposure to pesticides and their effects on health. With regard to issues of lack of national surveillance systems for the health of farm workers and inequalities related to access to services, researchers should be encouraged to review the health effects of pesticides among the related occupations in their studies. Assessing the impact of chronic low-dose exposure to pesticides and their effects on human health, particularly in young people is vital and studies on this population has an important impact on our ability in this area. The main strengths of this study were that the two groups were matched in terms of underlying factors and other factors were controlled in the analysis phase using statistical tests. Despite these strengths, the present study had several limitations. Being a retrospective study, recall bias, lack of access to accurate information related to exposure to toxins in days/years, and not studying the relationship in one type of cancer were the limitations of this study.

\section{Conclusion}

The results of this study showed that high exposure to pesticides increased the risk of cancers of the digestive tract. The adverse effects of these toxins on health have been shown in numerous studies. However, in some cities, these pesticides are still used in pistachio gardens. Raising the awareness of health officials, sensitizing the community toward the effects of these toxins, training people at risk, especially farmers, to control exposure to toxins, and reducing the burden caused by it are of particular importance.

\section{Acknowledgments}

Our sincere appreciation goes to the university officials, staff of the health centers in the city of Rafsanjan and Anar, and also the people who participated in this study.
Conflict of interest: None declared.

\section{References}

1. Etemadi A, Sadjadi A, Semnani S, Nouraie SM, Khademi H, Bahadori M. Cancer registry in Iran: a brief overview. Arch Iran Med 2008; 11(5):577-80.

2. almasi A, shamsi $M$, eshrati $B$, farzam $R$, alimoradi $\mathrm{K}$, rahmati L. The epidemiology of gastrointestinal cancers (Stomach, esophageal, colorectal) In Markazi province during 20052010. Journal of Neyshabur University of Medical Sciences 2014; 2(2):22-7.

3. Naghavi M. Death report from 23 provinces in Iran. $1^{\text {st }}$ ed. Tehran: Ministry of Health and Medical Education; 2004.

4. Mosavi-Jarrahi A, Mohagheghi MA. Epidemiology of esophageal cancer in the highrisk population of Iran. Asian Pac J Cancer Prev 2006; 7(3):375-80.

5. Pourhoseingholi MA, Vahedi M, MoghimiDehkordi B, Pourhoseingholi A, Ghafarnejad $\mathrm{F}$, Maserat E, et al. Burden of hospitalization for gastrointestinal tract cancer patients-Results from a cross-sectional study in Tehran. Asian Pac J Cancer Prev 2009; 10(1):107-10.

6. Sadjadi A, Nouraie M, Mohagheghi MA, Mousavi-Jarrahi A, Malekezadeh R, Parkin DM. Cancer occurrence in Iran in 2002, an international perspective. Asian Pac J Cancer Prev 2005; 6(3):359-63.

7. Ghadimi R, Taheri H, Suzuki S, Kashifard M, Hosono A, Esfandiary I. Host and environmental factors for gastric cancer in Babol, the Caspian Sea Coast, Iran. Eur J Cancer Prev 2007; 16(3):192-5.

8. Ramezani B, Hanifi A. Geographical distribution of gastric cancer in Guilan province. Journal of Environmental Science and Technology 2011; 13:81-93.

9. Blair A, Freeman LB. Epidemiologic studies in agricultural populations: observations and future directions. J Agromedicine 2009; 14(2):125-31.

10. Tavakolian Ferdosieyeh V, Karimifared M, Esmaeili A, Hassanshahi GH, Vazirinejad R. Pesticide induced complications among pistachio farmers: In the rural area of Rafsanjan, Iran (2010). Journal of Occupation Health and Epidmiology 2012; 1(2):111-7.

11. Salerno C, Carcagnì A, Sacco S, Palin LA, Vanhaecht K, Panella M, et al. An Italian population-based case-control study on the association between farming and cancer: are 
pesticides a plausible risk factor? Arch Environ Occup Health 2015; 71(3):147-56.

12. Alexander DD, Weed DL, Mink PJ, Mitchell ME. A weight-of-evidence review of colorectal cancer in pesticide applicators: the agricultural health study and other epidemiologic studies. Int Arch Occup Environ Health 2012; 85(7):715-45.

13. Yildirim M, Kaya V, Yildiz M, Demirpence O, Gunduz S, Dilli UD: Esophageal cancer, gastric cancer and the use of pesticides in the southwestern of Turkey. Asian Pac J Cancer Prev 2014; 15(6):2821-3.

14. Andreotti G, Freeman LEB, Hou L, Coble J, Rusiecki J, Hoppin JA, et al. Agricultural pesticide use and pancreatic cancer risk in the Agricultural Health Study Cohort. Int J Cancer 2009; 124(10):2495-500.

15. Rusiecki JA, De Roos A, Lee WJ, Dosemeci M, Lubin JH, Hoppin JA, et al. Cancer incidence among pesticide applicators exposed to atrazine in the Agricultural Health Study. J Natl Cancer Inst 2004; 96(18):1375-82.

16. Meyer A, Alexandre PC, Chrisman Jde R, Markowitz SB, Koifman RJ, Koifman S. Esophageal cancer among brazilian agricultural workers: case-control study based on death certificates. Int J Hyg Environ Health 2011; 214(2):151-5

17. Andreotti G, Freeman LE, Hou L, Coble J, Rusiecki J, Hoppin JA, et al. Agricultural pesticide use and pancreatic cancer risk in the Agricultural Health Study Cohort. Int J Cancer 2009; 124(10):2495-500.

18. Lee WJ, Alavanja MC, Hoppin JA, Rusiecki JA, Kamel F, Blair A, et al. Mortality among pesticide applicators exposed to chlorpyrifos in the Agricultural Health Study. Environ Health Perspect 2007; 115(4):528-34.
19. Samanic C, Rusiecki J, Dosemeci M, Hou L, Hoppin JA, Sandler DP, et al. Cancer incidence among pesticide applicators exposed to dicamba in the Agricultural Health Study. Environ Health Perspect 2006; 114(10):1521-6.

20. Van Bemmel DM, Visvanathan K, BeaneFreeman LE, Coble J, Hoppin J, Alavanja MC. S-ethyl-N, Ndipropylthiocarbamate exposure and cancer incidence among male pesticide applicators in the agricultural health study: a prospective cohort. Environ Health Perspect 2008; 116(11):1541-6.

21. Koutros S, Lynch CF, Ma X, Lee WJ, Hoppin JA, Christensen $\mathrm{CH}$, et al. Heterocyclic aromatic amine pesticide use and human cancer risk: results from the U.S. Agricultural Health Study. Int J Cancer 2009; 124(5):1206-12.

22. Weichenthal S, Moase C, Chan P. A review of pesticide exposure and cancer incidence in the Agricultural Health Study cohort. Environ Health Perspect 2010; 118(8):1117-25.

23. Amizadeh M, Askari Saryazdi G. Effects of endosulfan on human health. WebmedCentral TOXICOLOGY 2011; 2(12):WMC002617. doi: 10.9754/journal.wmc.2011.002617.

24. Mannan S. The effects of endosulfan on human MCF-7 breast cancer cells. [MSc Thesis]. Oshawa: University of Ontario Institute of Technology; 2011.

25. Reynolds P, Hurley SE, Gunier RB, Yerabati S, Quach T, Hertz A. Residential proximity to agricultural pesticide use and incidence of breast cancer in the California, 1988-1997. Environ Res 2005; 113(8):993-1000.

26. Zare S, Behzadi M, Tarzanan M, Mohamadi MB, Omidi L, Heydarabadi AB, et al. The impacts of pesticides on the health of farmers in Fasa, Iran. Electron Physician 2015; 7(4):1168-73. 